\title{
Early remodelling of coronary stenoses after thrombolytic treatment in patients with acute myocardial infarction
}

\author{
Dimitris Tousoulis, Felicita Andreotti, David Hackett, Agha W Haider, Attilio Maseri, \\ Graham Davies
}

\begin{abstract}
Objective-To assess the frequency of early remodelling of coronary stenosis morphology after thrombolytic treatment in patients with acute myocardial infarction.

Design-Coronary angiograms were analysed by a computerised edge detection analysis system. Coronary stenosis severity was measured and morphology classified as smooth or complex.

Patients-Coronary arteriograms were obtained approximately $90 \mathrm{~min}$ and $24 \mathrm{~h}$ after thrombolytic treatment from 40 patients with acute myocardial infarction. Main results-Stenosis morphology was complex in 22 patients $(65 \%)$ and smooth in $11(32 \%) 90 \mathrm{~min}$ after thrombolysis. The morphology of 11 (50\%) complex coronary stenoses and three (27\%) smooth stenoses had changed at $24 \mathrm{~h}(\mathbf{P}<$ $0 \cdot 05)$. The transition from complex to smooth was associated with a reduction in stenosis severity from 65 (4)\% to 51 (5)\% $(\mathbf{P}<0.05)$. The stenosis severity was $63(4) \%$ and $60(5) \%$ in those with persistently complex morphology, and 56 (7)\% and $50(5) \%$ in those with persistently smooth morphology at $90 \mathrm{~min}$ and $24 \mathrm{~h}$ respectively (NS).

Conclusions-Transition of morphology from complex to smooth within $24 \mathrm{~h}$ is common. This transition is associated with a reduction in stenosis severity of a degree greater than that found in persistently smooth stenoses over the same interval. $50 \%$ of stenoses are smooth at 24 h.
\end{abstract}

(Br Heart F 1995;74:229-234)

Royal Postgraduat Medical School,

Hammersmith Hospital, London D Tousoulis F Andreotti D Hackett A W Haider G Davies

Institute of Cardiology, Catholic University, Largo F. Vito 1, 00168 Roma, Italy

A Maseri

Correspondence to: Dr G Davies, Clinical Cardiology Unit, Hammersmith Hospital Ducane Road, London W12 0NN

Accepted for publication 3 January 1995 irregular border. The severity of resid stenosis is variable $^{23}$ and despite successful thrombolysis 15-25 per cent of patients develop early reocclusion. ${ }^{127}$ There is evidence that remodelling of residual stenosis occurs after treatment, ${ }^{24}$ but the relation between early coronary stenosis morphology and remodelling has not previously been described. We therefore investigated the angiographic morphology and severity of the residual infarct related coronary stenosis at approximately $90 \mathrm{~min}$ and $24 \mathrm{~h}$ after the start of streptokinase or tissue plasminogen activator (rtPA) treatment in patients with acute myocardial infarction.

\section{Patients and methods}

\section{STUDY PATIENTS}

Forty consecutive patients ( 31 men and nine women of mean (SEM) (range) age 55 (7) (36-71) years presenting with their first myocardial infarction were included in the study. All presented with persistent chest pain typical of acute myocardial ischaemia of more than $30 \mathrm{~min}$ duration and electrocardiographic ST segment elevation $(\geqslant 0.2 \mathrm{mV}$ in $\geqslant$ two leads of the standard 12 lead surface electrocardiogram) resistant to a $2 \mathrm{mg}$ intravenous bolus of isosorbide dinitrate. The duration of chest pain at the time of initiation of fibrinolytic treatment was $<6 \mathrm{~h}$ in all cases. Patients were included in the study only if they were able to give fully informed, written consent to the study. They were excluded from the study if any of the following were present: (1) conditions that increased the risk of haemorrhagic complication with thrombolytic treatment; (2) cardiogenic shock (systolic blood pressure $<80 \mathrm{~mm} \mathrm{Hg}$ ) or pulmonary oedema; and (3) severely impaired renal or hepatic function.

The study protocol was approved by the Research Ethics Committee of Hammersmith Hospital. As soon as possible after admission patients were transferred to the cardiac catheterization laboratory from the accident and emergency department or from the coronary care unit. After insertion of short femoral arterial and venous sheaths a bolus of 5000-10 000 IU of heparin was administered intravenously. Intracoronary isosorbide dinitrate $(2 \mathrm{mg})$ was administered into the ostium of the infarct related artery followed by a $2 \mathrm{ml}$ saline flush.

Fourteen patients received a continuous intracoronary infusion of streptokinase (5000 $\mathrm{IU} / \mathrm{ml}$ normal saline at $1 \mathrm{ml} / \mathrm{min}$ ). The streptokinase infusion was continued throughout the procedure until stable patency of the 
infarct related artery was achieved or a maximum dose of 600000 IU had been administered (total duration $120 \mathrm{~min}$ ). Some 14 patients received an intravenous infusion of 40 clot lysis MU of double chain rtPA (alteplase) over $90 \mathrm{~min}$, followed by infusion of $20 \mathrm{MU}$ over $5 \mathrm{~h}$ (cumulative dose $60 \mathrm{MU}$ ); 12 patients received four intravenous bolus injections of 10 clot lysis MU of double chain $\mathrm{rtPA}$ at $20 \mathrm{~min}$ intervals (total duration 60 $\min$ ).

Coronary arteriography was repeated about 90 (range 60-120) min after the start of fibrinolytic treatment and also in the event of relief of chest pain or resolution of ST segment elevation. This coronary arteriogram is subsequently referred to as the $90 \mathrm{~min}$ arteriogram. At the end of the procedure the femoral arterial and venous sheaths were left in situ and the patients were transferred to the coronary care unit. Patency of the sheaths was maintained by slow infusion of heparinized saline and an intravenous infusion of heparin was administered over a period of $24 \mathrm{~h}$ to maintain an activated partial thromboplastin time of two to three times normal. An intravenous infusion of glyceryl trinitrate was administered at a rate of $1-10 \mathrm{mg} / \mathrm{h}$ titrated against systolic blood pressure. Oral aspirin (75 mg daily) and diltiazem (60 mg every $8 \mathrm{~h}$ ) were prescribed. Coronary arteriography was repeated about 24 (range 18-36) h later. This coronary arteriogram is subsequently referred to as the $24 \mathrm{~h}$ arteriogram. After this arteriogram patients received routine clinical care.

\section{QUANTITATIVE CORONARY ANGIOGRAPHY}

The state of perfusion of the infarct related vessel on the coronary arteriograms was graded by two blinded observers from 0 (complete occlusion) to 3 (full patency), according to the classification criteria of the Thrombolysis In Myocardial Infarction (TIMI) Study Group. ${ }^{25}$ We defined coronary occlusion as TIMI grade 0 or 1 and patency as grade 2 or 3 . Coronary artery stenoses were analysed in random order using quantitative computerised analysis with an automated edge contour detection analysis system (Computerized Angiographic Analysis System (CAAS), Version 2V2; Pie Data Medical, Maastricht, The Netherlands).$^{26}$ End diastolic frames from each arteriogram were selected for analysis. The angiographic catheter was used as a scaling device and this together with pincushion distortion correction allowed the diameters to be recorded as absolute values (expressed in $\mathrm{mm}$ ). Recorded variables before, 60-120 min after thrombolysis, and after $24 \mathrm{~h}$ were: (1) the location of stenoses, defined as the site of minimal lumen diameter relative to side branch origins; (2) the minimum diameter of stenoses in $\mathrm{mm}$; (3) minimum luminal diameter as a percentage of that of the adjacent "normal" segment; and (4) qualitative and quantitative classification of stenosis morphology.

Stenoses were morphologically classified qualitatively as smooth (concentric or eccentric) or "complex" by two blinded indepen- dent observers on the basis of visual inspection of arteriograms recorded in two orthogonal projections. This classification of stenoses into concentric or eccentric was compared with that obtained by computerised symmetry analysis (CAAS symmetry index $)^{27} 28$ of the same coronary lesions. The symmetry index was measured from the predefined centre line of the vessel and given a value between 0 and 1 , with 1 representing a perfectly concentric lesion and 0 representing the most severe case of eccentric lesion. Concentric stenoses were defined as those producing symmetric narrowing, with smooth borders or only very mild irregularity (symmetry index $>0.5-1$ ) that looked sinuilar in orthogonal projections. Eccentric stenoses were defined as asymmetric narrowing with smooth borders and a broad neck (symmetry index $0 \cdot 0-\leqslant 0 \cdot 5)$. Complex stenoses were defined as asymmetric narrowings with irregular borders or overhanging edges, or type II of Ambrose $e t a l,{ }^{17}{ }^{18}$ or both, or with an "abrupt proximal face"19 or a "rough" or "sawtooth" component. ${ }^{19}$

Coronary stenosis remodelling was defined as a change in morphology from smooth (eccentric or concentric) to complex, or to occlusion, and vice versa. Clear angiographic evidence of intraluminal thrombus was found in three patients and was analysed as a part of the stenoses. A change in stenosis severity was not required to define remodelling. However, the completely occluded vessels at $90 \mathrm{~min}$ were unclassifiable. Quantitative analysis of coronary arteriograms was carried out by two independent observers, who blindly reanalysed the films at a remote time for reproducibility of the method. No significant intra- or inter-observer variability was found $(F=0.3, P=0.75)$. The inter/intraobserver variability for the qualitative assessment of stenosis morphology was 95 per cent and 98 per cent respectively and any differences in classification were resolved by consensus. Agreement between computer symmetry analysis and qualitative assessment was 98 per cent for lesions imaged at baseline. In a separate study, we analysed the intra- and interobserver variability of the CAAS system in our institution. Twenty four arterial segments were analysed by two independent observers and reanalysed at a remote time. The mean intraobserver variation, expressed as the standard error of the estimate (SEE), was 0.12 $\mathrm{mm}$. The interobserver variation (SEE) was $0.10 \mathrm{~mm}$.

\section{STATISTICAL ANALYSIS}

All data are expressed as mean (SEM). For comparisons of haemodynamic data and coronary artery diameters (in $\mathrm{mm}$ ), a one-way analysis of variance, with an allowance for repeated measures, was performed. When an $F$ value was found to be significant, a two tailed Student's $t$ test for paired observations with the Bonferroni correction was used to test differences among means. Discrete data were analysed by the $\chi^{2}$ test. A P value $<0.05$ was considered significant. 
Results

PATIENT CHARACTERISTICS

Twenty six patients received rtPA within $3 \cdot 0$ $(0.22) \mathrm{h}$ of the onset of symptoms: $10 \mathrm{had}$ anterior ST segment elevation with left anterior descending artery occlusion, 11 had inferior ST segment elevation with right coronary artery occlusion, and five had true posterolateral ST segment change with dominant circumflex coronary artery occlusion.

Fourteen patients received streptokinase within $2 \cdot 8(0.32) \mathrm{h}$ of the onset of symptoms: six had anterior ST segment elevation with left anterior descending artery occlusion, five had inferior ST segment elevation with right coronary artery occlusion, and three had true posterolateral ST segment change with dominant circumflex coronary artery occlusion.

The infarct related coronary arteries were patent (TIMI grade 2 or 3 ) in two patients receiving streptokinase and two receiving rtPA before thrombolytic treatment, but with an angiographic filling defect suggestive of intraluminal thrombus; these patients were included in the study. The infarct related stenosis morphology was complex in two of these patients.

\section{STENOSIS SEVERTTY AND MORPHOLOGY 90 MIN} AFTER TREATMENT

Some $90 \mathrm{~min}$ after fibrinolytic treatment the infarct related artery was patent in 34 patients ( 85 per cent) (12 after streptokinase and 22 after rtPA) with a minimum luminal diameter at the site of residual stenosis of $1.16(0 \cdot 10)$ $\mathrm{mm}$. The residual stenosis morphology was complex in 22 patients (65 per cent) and smooth in 11 (32 per cent) $(\mathrm{P}<0.01)$. There was no residual stenosis in one patient. The minimum luminal diameter was $1.07(0.09)$ $\mathrm{mm}$ at complex stenoses and $1.19(0.20) \mathrm{mm}$ at smooth stenoses ( $P=$ not significant). There was no difference in patency rate $(86$ per cent $v 84$ per cent) or minimum luminal diameter $(1.12(0.15)$ v $1.18 \quad(0.13) \mathrm{mm})$ between streptokinase and tPA treated patients.

STENOSIS SEVERITY AND MORPHOLOGY AT $24 \mathrm{H}$ At $24 \mathrm{~h}$ the infarct related artery was patent in 32 (80 per cent) patients ( 12 after streptokinase and 20 after rtPA) with a minimum luminal diameter of $1.33(0.11) \mathrm{mm}$. The stenosis morphology was complex in 14 patients (44 per cent) and smooth in 16 (50 per cent), and there was no residual stenosis in two. The minimum luminal diameter was $1.15(0.13) \mathrm{mm}$ at complex stenoses and 1.32 $(0 \cdot 13) \mathrm{mm}$ at smooth stenoses $(\mathrm{P}=$ not significant). There was no difference in patency rate (86 per cent $v 77$ per cent) or minimum luminal diameter $(1.32(0.18)$ v $1.34(0.14)$ $\mathrm{mm})$ between streptokinase and rtPA treated patients.

\section{CHANGE IN STENOSIS SEVERTTY AND MORPHOLOGY}

At $24 \mathrm{~h}$ remodelling of morphology was observed in 11 of 22 (50 per cent) complex coronary stenoses (four lesions had occluded and seven had become smooth) and in three of 11 (27 per cent) smooth stenoses (one lesion had occluded, one had become complex, and one had become a normal segment). The difference in the incidence of remodelling and reocclusion of smooth and complex stenoses over time was significant $(P<0.05)$. The transition of seven stenoses from complex to smooth was associated with a reduction in stenosis severity from 65 (4) to 51 (5) per cent $(P<0.05)$ and with an increase in the mean luminal diameter from $0.95(0.15)$ to $1.41(0.24) \mathrm{mm}(\mathrm{P}<0.05)$ (table 1 , figs 1 and 2 ). In contrast, in those with persistent complex morphology severity was 63 (4) and 60 (5) per cent, at $90 \mathrm{~min}$ and $24 \mathrm{~h}$, and in those with persistent smooth $(n=8)$ morphology it was 56 (7) and 50 (5) per cent respectively ( $\mathrm{P}=$ not significant) (table 1$)$.

Before thrombolytic treatment TIMI flow

Table 1 Minimum luminal diameter and severity after thrombolysis of complex stenoses with persistently complex morphology or transition to smooth morphology

\begin{tabular}{|c|c|c|c|c|c|c|}
\hline \multirow[b]{2}{*}{ No of stenoses } & \multicolumn{3}{|l|}{$90 \mathrm{~min}$} & \multicolumn{3}{|l|}{$24 h$} \\
\hline & Morphology & $\begin{array}{l}\text { Diameter } \\
(\mathrm{mm})\end{array}$ & $\begin{array}{l}\text { Severity } \\
(\%)\end{array}$ & Morphology & $\begin{array}{l}\text { Diameter } \\
(\mathrm{mm})\end{array}$ & $\begin{array}{l}\text { Severity } \\
(\%)\end{array}$ \\
\hline $\begin{array}{r}7 \\
11\end{array}$ & $\begin{array}{l}\text { Complex } \\
\text { Complex }\end{array}$ & $\begin{array}{c}0.95(0.15) \\
1.16(0.15)\end{array}$ & $\begin{array}{l}65 \cdot 0(4) \\
63 \cdot 0(4)\end{array}$ & $\begin{array}{l}\text { Smooth } \\
\text { Complex }\end{array}$ & $\begin{array}{l}1.41(0.24)^{\star} \\
1.321(0.15)\end{array}$ & $\begin{array}{l}51.0(5) \dagger \\
60.0(5)\end{array}$ \\
\hline
\end{tabular}

$\star^{\star} \mathrm{P}<0.05$ compared with minimum luminal diameter at $90 \mathrm{~min} ;+\mathrm{P}<0.05$ compared with severity at 90 min. Student's paired $t$ test.

Table 2 Patency of the infarct related coronary artery before, and 90 min and $24 \mathrm{~h}$ after thrombolytic treatment

\begin{tabular}{|c|c|c|c|c|c|c|}
\hline \multirow{2}{*}{$\begin{array}{l}\text { Coronary patency } \\
\text { (TIMI grade) }\end{array}$} & \multicolumn{3}{|c|}{ Arteries with remodelling } & \multicolumn{3}{|c|}{ Arteries without remodelling } \\
\hline & Before & $90 \mathrm{~min}$ & $24 h$ & Before & $90 \min$ & $24 h$ \\
\hline $\begin{array}{l}0 \\
1 \\
2 \\
3\end{array}$ & $\begin{array}{l}7 \\
4 \\
2 \\
1\end{array}$ & $\begin{array}{c}0 \\
0 \\
2^{\star} \\
12^{\star}\end{array}$ & $\begin{array}{l}4 \\
1 \\
0 \\
9\end{array}$ & $\begin{array}{r}23 \\
2 \\
0 \\
1\end{array}$ & $\begin{array}{c}6 \\
0 \\
1 \dagger \\
19\end{array}$ & $\begin{array}{r}3 \\
0 \\
1 \\
22\end{array}$ \\
\hline
\end{tabular}

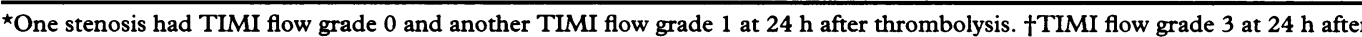
thrombolysis. TIMI, thrombolysis in myocardial infarction. 

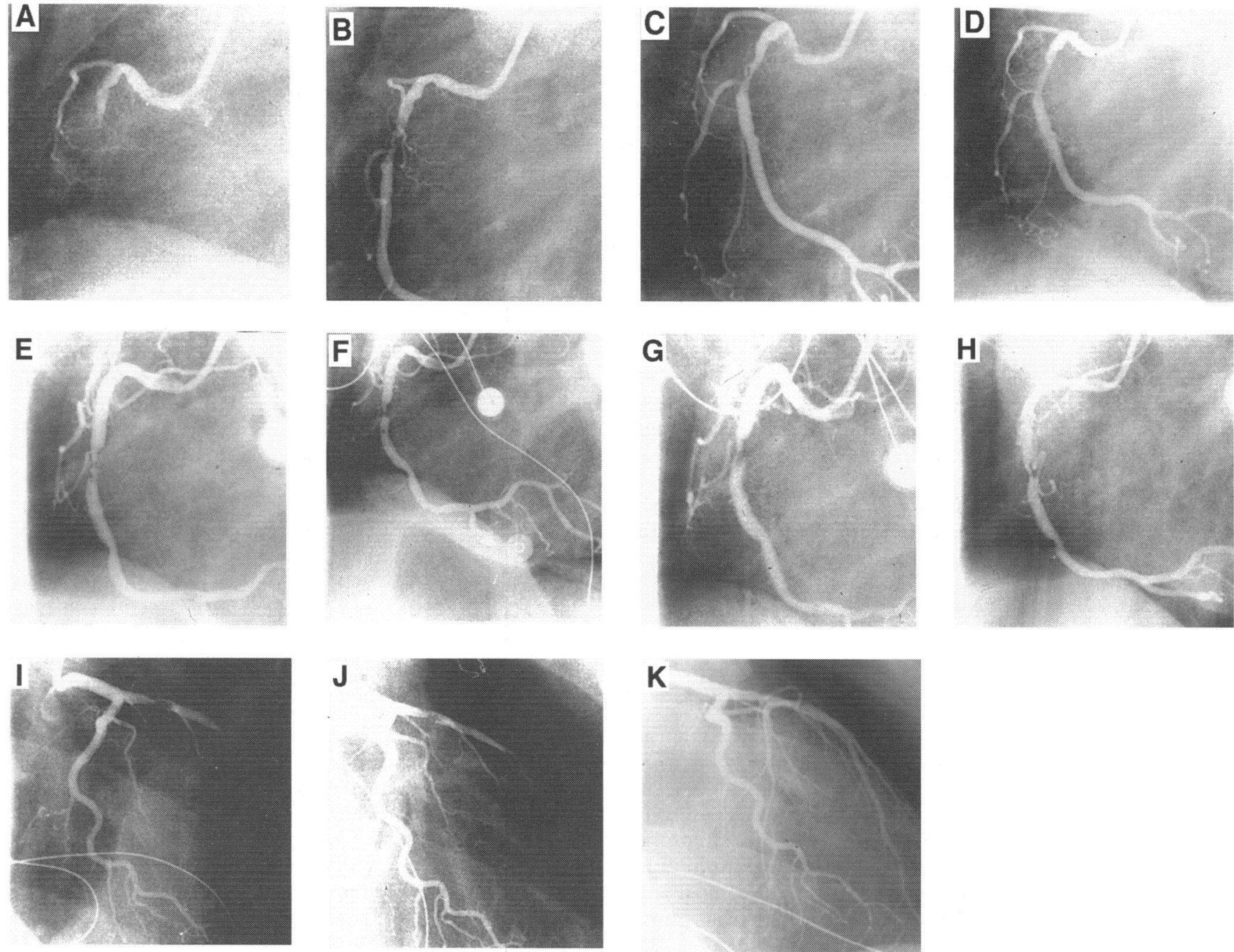

Figure 1 Coronary angiograms showing examples of remodelling of complex coronary stenoses to a smooth morphology $24 \mathrm{~h}$ after thrombolysis. Top: right coronary arteriograms (A) before, (B) during, and (C) 90 min and (D) 24 h after thrombolytic treatment. The occluded artery has become patent with a severe complex stenosis during treatment; the stenosis is less complicated at 90 min and mild and smooth at $24 \mathrm{~h}$. Middle: right coronary arteriograms (E) before, $(F)$ during, and $(G) 90$ min and $(H) 24$ h after thrombolytic treatment. The stenosis is complex before treatment; it is severe but less complex during treatment and a small piece of thrombus has broken off. It has become smooth but is still severe at $24 \mathrm{~h}$. Bottom: left coronary arteriograms (I) before, and (f) $90 \mathrm{~min}$ and $(K) 24 \mathrm{~h}$ after thrombolytic treatment. The stenosis remains complex at 90 min but is a little less severe. It has become smooth and very mild by $24 \mathrm{~h}$.

grades $0,1,2$, and 3 were found in 30 , six, two and two arteries respectively. Some 90 min after thrombolytic treatment TIMI flow grades 0,2 , and 3 were found in six, three, and 31 arteries respectively. At $24 \mathrm{~h}$ after thrombolytic treatment TIMI flow grades 0 , 1,2 , and 3 were found in 7 , one, one, and 31
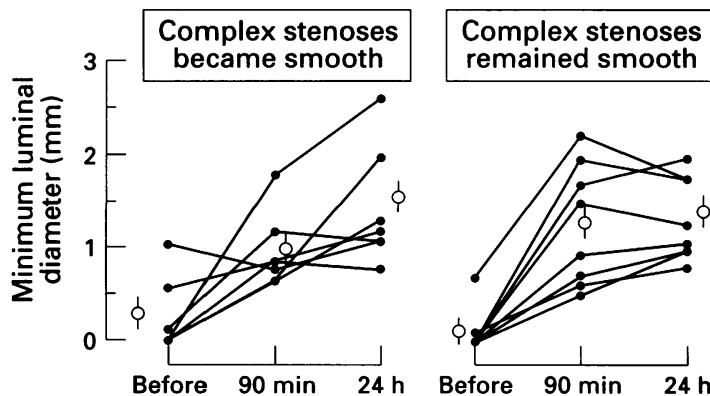

Complex stenoses remained complex

Figure 2 Coronary stenosis expressed as minimum luminal diameter in individual patients, before, and 90 min and $24 \mathrm{~h}$ after thrombolytic treatment. Mean (SEM) is shown. arteries respectively (table 2). Of the 11 complex stenoses that remodelled between $90 \mathrm{~min}$ and $24 \mathrm{~h}, 10$ were associated with TIMI flow grade 3 and one with TIMI flow grade 2 at $90 \mathrm{~min}$. Of the three smooth stenoses that remodelled, two had TIMI flow grade 3 and one TIMI flow grade 2 at $90 \mathrm{~min}$. Both the stenoses with TIMI flow grade 2 at $90 \mathrm{~min}$ had become completely occluded by $24 \mathrm{~h}$. Table 2 shows the flow grades according to the presence or absence of remodelling.

Five of the 34 patent vessels became occluded at $24 \mathrm{~h}$, three of six occluded vessels became patent at $24 \mathrm{~h}$ yielding a total of 32 patent arteries at $24 \mathrm{~h}$. Three of eight occlusions at $24 \mathrm{~h}$ were unchanged from $90 \mathrm{~min}$, but five had developed from stenoses which previously were relatively mild (73 per cent, 44 per cent, 55 per cent, 59 per cent, 64 per cent) and four of these were complex. Three occlusions at $90 \mathrm{~min}$ after thrombolysis had become patent at $24 \mathrm{~h}$ (two with smooth morphology and one complex). 
Discussion

This study shows that considerable remodelling of residual coronary artery stenosis occurs in the first $24 \mathrm{~h}$ after initial patency has been obtained in response to thrombolytic drugs. Furthermore, the likelihood of remodelling is related to morphology of the residual lesion immediately after thrombolysis. Some $90 \mathrm{~min}$ after rtPA or streptokinase administration the infarct related artery was patent in $\mathbf{8 5}$ per cent of patients with a residual stenosis of variable severity in all but one patient. Sixty five per cent of these stenoses were of complex morphology and 32 per cent were of smooth. Remodelling of complex stenoses caused a transition between $90 \mathrm{~min}$ and $24 \mathrm{~h}$ to occlusion in 18 per cent and to smooth morphology in 32 per cent. Transition to smooth morphology was associated with a reduction in stenosis severity of a degree greater than that found in persistently smooth stenoses over the same time interval, the latter reaching a similar final luminal diameter at $24 \mathrm{~h}$ from a greater absolute diameter at $90 \mathrm{~min}$.

\section{CORRELATION BETWEEN ANGIOGRAPHIC} LESION MORPHOLOGY AND HISTOLOGICAL FINDINGS IN ACUTE MYOCARDIAL INFARCTION Previous studies ${ }^{17}{ }^{19}$ have described the close association between type of stenosis morphology and acute coronary syndromes. Ambrose et $a l^{171822}$ have shown that the type II eccentric lesion (smooth with narrow neck or irregular borders) is found in many patients with acute presentation of unstable angina and in those with acute or recent myocardial infarction without totally occluded vessels. Other angiographic studies have identified either intraluminal filling defects, consistent with thrombus, or eccentric lesions with irregular borders in patients with unstable angina. ${ }^{22} 2930$ The type II lesion is the most common morphological finding in infarct related vessels after reperfusion with streptokinase. Comparison of postmortem angiographic and histological findings in patients with coronary artery disease has shown that these irregular lesions may represent not only sites of intraluminal partially occlusive or partially lysed thrombus but also of plaque rupture, plaque haemorrhage, or organised thrombus. ${ }^{11} 2021 \mathrm{At}$ postmortem examination plaque rupture was found in 64 per cent of patients with unstable angina, 90 per cent of those with acute myocardial infarction and 38 per cent of those who had died suddenly and unexpectedly. ${ }^{31}$ Many patients in our study showed this complex stenosis morphology $90 \mathrm{~min}$ after coronary thrombolysis, but by $24 \mathrm{~h} 50$ per cent of stenoses were smooth. As ruptured plaques would be expected to have a complex morphology it raises the possibility that at least $\mathbf{5 0}$ per cent of patients who survive a myocardial infarction probably have not had a plaque rupture. This is in contrast to postmortem studies $^{1120}$ in which a higher incidence of plaque rupture has been reported. It is conceivable that myocardial infarction due to plaque rupture is more likely to be fatal than those caused by superficial thrombosis.
The importance of thrombus in the development of coronary occlusion in acute myocardial infarction is firmly established on the basis of previous studies of thrombolytic therapy. ${ }^{32-34}$ The infarct related coronary artery patency at any selected time of study may represent only a transient phase of a dynamic event involving dissolution and reformation of intracoronary thrombus. The intensity of the thrombotic stimulus may be related to the degree of vessel injury, but a systemic alteration in blood coagulability or low blood flow velocity, or both, may determine which fissured plaques are complicated by thrombotic occlusion.

\section{CORONARY LUMINAL REMODELLING}

Changes in coronary stenosis severity and morphology have been observed after successful thrombolysis in patients with myocardial infarction. ${ }^{24}{ }^{34}$ Davies et $a l^{24}$ showed, at repeat angiography 2-10 days after thrombolysis, that globular filling defects seen in eight patients had disappeared, while linear filling defects persisted in seven of 14 cases. Furthermore, with an increasing interval between thrombolysis and angiography, the observed frequency of irregular lesions and the ulceration index decreased. These changes have been attributed to reendothelisation of the ruptured plaque, resorption of associated haemorrhage, dissolution of residual thrombus as a result of continuing fibrinolysis, and altered vasomotor tone due to loss of endothelial function.

The results of the present study show that remodelling is an early phenomenon with considerable change in morphology and stenosis severity occurring within $24 \mathrm{~h}$ of initial patency. The process of remodelling and stabilization of the coronary plaque is marked by either a tendency to smoother less stenotic lesions or reocclusion. This transition from complex to smooth stenosis morphology would be compatible with healing of ruptured atheromatous plaque, but also with the further dissolution of thrombus or a combination of both mechanisms. We did not have follow up angiographic data indicating that the remodelled stenoses remained stable after 24 h. Other clinical studies, ${ }^{24}$ however, indicate that early angiographic appearance predicts reocclusion at 3 months and that smooth stenoses seem to be more stable than complex stenoses. It is uncertain to what extent this early remodelling reflects the natural history or the effect of treatment, which included aspirin and heparin. Serruys et $a l^{35}$ found an improvement in the per cent diameter stenosis and plaque area in patients maintained on heparin treatment after thrombolysis with recombinant rtPA, but morphological characteristics were not examined.

Almost all the infarct related arteries in this study were either occluded or had TIMI flow grade 3 at $90 \mathrm{~min}$ and no definite relation between TIMI flow grade and remodelling was found. 


\section{CLINICAL IMPLICATIONS}

Smooth residual lesions seem to be more stable than complex ones. The relatively rapid morphological change therefore probably indicates a rapid process of stabilisation of the active coronary lesion. Further studies are required to investigate whether additional treatment after thrombolysis can accelerate the transition to stability. Use of early coronary arteriography to detect complex lesions might then be used to identify a subgroup of patients requiring additional treatment such as angioplasty or anticoagulation.

\section{Conclusions}

The likelihood of remodelling depends on the morphology of residual coronary stenosis immediately after thrombolysis. Complex coronary stenosis morphology $90 \mathrm{~min}$ after thrombolytic treatment represents an unstable state which tends to change within $24 \mathrm{~h}$, to either occlusion or a smooth residual stenosis of lesser severity. Smooth coronary morphology tends to remain stable with persistent patency.

1 Braunwald E. Myocardial reperfusion, limitation of infarct size, reduction of left ventricular dysfunction and improved survival: should the paradigm be expanded? Circulation 1989;79:441-4.

2 Braunwald E. Optimizing thrombolytic therapy of acute myocardial infarction (editorial). Circulation 1990;82. $1510-3$.

3 O'Rourke M, Baron D, Keogh A, Kelly R, Nelson G, Barnes $\mathrm{C}$, et al. Limitation of myocardial infarction by early infusion of recombinant tissue-type plasminogen activator. Circulation 1988;77:1311-5.

4 Kennedy JW, Martin GV, Davis KB, Maynard C, Stadius $M$, Sheehan FH, et al. The Western Washington intravenous streptokinase in acute myocardial infarction randomized trial. Circulation 1988;77:345-52.

5 White HD, Norris RM, Brown MA, Takayama $M$, Maslowski A, Bass NM, et al. Effects of intravenous streptokinase on left ventricular function and early survival after acute myocardial infarction. $N$ Engl $f \mathrm{Med}$ 1987;317:850-5.

6 Bassand J-P, Faivre R, Becque O, Habert C, Schuffenecker M, Patiteau PY, et al. Effects of early high-dose streptokinase intravenously on left ventricular function in acute myocardial infarction. $A m \ngtr$ Cardiol function in acu

7 Braunwald E. Coronary artery patency in patients with myocardial infarction. $¥ \mathrm{Am}$ Coll Cardiol 1990;16: myocardial $1550-2$.

8 Lierde JV, Geest H, Verstraete M, Werf VF. Angiographic assessment of the infarct-related residual coronary stenosis after spontaneous or therapeutic thrombolysis. $\mathcal{f} A m$ Coll Cardiol 1990;16:1545-9.

9 Duber C, Jungbluth A, Rumpelt HJ, Erbel R, Meyer J, Thoenes $W$. Morphology of the coronary arteries after combined thrombolysis and percutaneous transluminal coronary angioplasty for acute myocardial infarction. $\mathrm{Am}$ $¥$ Cardiol 1986;58:698-703.

10 Wilensky RL, Bourdillon PDV, Vix VA, Zeller JA Intracoronary artery thrombus formation in unstable angina: a clinical biochemical and angiographic correlation. $\mathcal{F}$ Am Coll Cardiol 1993;21:692-9.

11 Falk E. Plaque rupture with a severe pre-existing stenosis precipitating coronary thrombosis: characteristics of coronary atherosclerotic plaques underlying fatal occlusive thrombi. Br Heart $\mathcal{f} 1983 ; 50: 127-34$.

12 Levin DC, Fallon JT. Significance of the angiographic morphology of localized coronary stenoses: histopathomorphology of localized coronary stenoses: hist

13 Ridolf RL, Hutchins GM. The relationship between coronary lesions and myocardial infarctions; ulceration of atherosclerotic plaques precipitates coronary thrombosis. Am Heart $\mathcal{F}$ 1977;93:468-86.
14 Wilson RF, Holida BS, White CW. Quantitative angiographic morphology of coronary stenoses leading to myocardial infarction or unstable angina. Circulation 1986;73:286-93.

15 Harrison DG, Ferguson DW, Collins SM, Skorton DJ, Ericksen EE, Kioschos MJ, et al. Rethrombosis after reperfusion with streptokinase: importance of geometry
of residual lesions. Circulation 1984;69:991-9.

16 Brown BG, Gallery CA, Badger RS, Kennedy JW, Mathey $\mathrm{D}$, Bolson EL, et al. Incomplete lysis of thrombus in the moderate underlying atherosclerotic lesion during intracoronary infusion of streptokinase for acute myocardial infarction: quantitative angiographic observations. Circulation 1986;73:653-61.

17 Ambrose JA, Winters SL, Arora RR, Halt JI, Goldstein J, Rentrop KP, et al. Coronary angiographic morphology in myocardial infarction: a link between the pathogenesis of unstable angina and myocardial infarction. $\mathfrak{f} \mathrm{Am} \mathrm{Coll}$ of unstable angina and

18 Ambrose JA, Winters SL, Arora RR, Eng A, Riccio A, Gorlin $\mathrm{R}$, et al. Angiographic evolution of coronary artery morphology in unstable angina. $\mathcal{F} \mathrm{Am}$ Coll Cardio 1986;7:472-8.

19 Ellis S, Alderman EL, Cain K, Wright A, Bourassa M Fisher L. Morphology of left anterior descending coronary territory lesions as a predictor of anterior myocardial infarction: a CASS registry study. $₹ \mathrm{Am}$ Coll Cardio 1989;13:1481-91.

20 Davies MJ, Thomas AC. Plaque fissuring - the cause of acute myocardial infarction, sudden ischaemic death and crescendo angina. Br Heart $₹$ 1985;53:363-73.

21 Davies MI, Thomas A. Thrombosis and acute coronary lesions in sudden cardiac ischemic death. N Engl $₹$ Med 1984;310:1137-40.

22 Ambrose JA, Winters SL, Stern A, Eng A, Teichholz LE, Gorlin $\mathrm{R}$, et al. Angiographic morphology and the pathogenesis of unstable angina pectoris. $\mathcal{F} \mathrm{Am}$ Coll Cardio 1985;5:609-16

23 Hackett D, Davies G, Maseri A. Pre-existing coronary stenoses in patients with first myocardial infarction are not necessarily severe. Eur Heart $\mathcal{F}$ 1988;9:1317-23.

24 Davies SW, Marchard B, Lyons JP, Timmis AD, Rothman MT, Layton CA, et al. Coronary lesions morphology in acute myocardial infarction: demonstration of early remodeling after streptokinase treatment. $7 \mathrm{Am}$ Coll Cardiol 1990;16:1079-86.

25 The TIMI Study Group. The thrombolysis in myocardial infarction (TIMI) trial: phase 1 findings. $N$ Engl $\mathcal{F} \mathrm{Med}$ 1985;312:932-6.

26 Reiber JHC, Serruys PW, Koouman C, Wijns W, Slager C, Gerbrands J, et al. Assessment of short-, medium, and long-term variations in arterial dimensions from computer-assisted quantitation of coronary cineangiograms. Circulation 1985;71:280-8.

27 Tousoulis D, Kaski JC, Davies G, Pereira W, El-Tamim $\mathrm{H}, \mathrm{McF}$ adden E, et al. Preangioplasty complicated coronary stenosis morphology as a predictor to restenosis. Am Heart f 1992;123:15-20.

28 Kaski JC, Tousoulis D, Haider W, Gavrielides S, Crea F, Maseri A. Reactivity of eccentric and concentric stenose in chronic stable angina. F Am Coll Cardiol 1991;17: 627-33.

29 Cowley MJ, DiSciasco G, Rehr RB, Vetrovec GW. Angiographic observations and clinical relevance of coronary thrombus in unstable angina pectoris. $A m \mathcal{F}$ Coronary thrombus in un
Cardiol $1989 ; 63: 108-13 \mathrm{E}$.

30 Gotoh K, Minamino T, Katoh O, Hamano Y, Funui S, Hori $M$, et al. The role of intracoronary thrombus in unstable angina: angiographic assessment and thrombolytic therapy during ongoing anginal attacks. bolytic therapy during

31 Kragel AH, Gertz DS, Roberts WC. Morphologic comparison of frequency and types of acute lesions in the majo epicardial coronary arteries and unstable angina pectoris, sudden coronary death and acute myocardial infarction. $\mathcal{F}$ Am Coll Cardiol 1991;18:801-8.

32 Laffel GL, Braunwald E. Thrombolytic therapy: a new strategy for the treatment of acute myocardial infarction. $N$ Engl f Med 1984;311:710-7.

33 Davies GJ, Chierchia S, Maseri A. Prevention of myocardial infarction by very early treatment with intracoronar streptokinase: some clinical observations. $N$ Engl f Med 1984;311:1488-92.

34 Hackett D, Davies GJ, Chierchia S, Maseri A. Intermittent coronary occlusion in acute myocardial infarction: value of combined thrombolytic and vasodilator therapy. N Engl F Med 1987;317:1055-9.

35 Serruys PW, Arnold AER, Brower RW, De Bono DP, Bokslag M, Lubsen J, et al for the European Cooperative Study Group for recombinant tissue-type plasminogen activator. Effect of continued rt-PA administration on the residual stenosis after initially successful recanalization in acute myocardial infarction: a quantitative coronary study of a randomized trial. Eur Heart $\mathcal{f} 1987 ; 8$ : 1172-81. 